\title{
Significance of prophylactic intra-abdominal drain placement after laparoscopic distal gastrectomy for gastric cancer
}

Noriyuki Hirahara*, Takeshi Matsubara, Hikota Hayashi, Kiyoe Takai, Yusuke Fujii and Yoshitsugu Tajima

\begin{abstract}
Background: Unnecessary intra-abdominal drain insertion must be avoided, but little is known about the value of prophylactic drainage following laparoscopic distal gastrectomy (LDG). In this study, we investigated the significance of prophylactic drain placement after LDG for gastric cancer.

Methods: Seventy-eight consecutive patients with gastric cancer who underwent LDG in our department were retrospectively analyzed. The patients were divided into two groups according to the insertion of a prophylactic intra-abdominal drain following LDG. The 'drain group' comprised 45 patients with routine use of a prophylactic intra-abdominal drain, and the 'no-drain group' comprised 33 patients who did not undergo placement of an intra-abdominal drain.

Results: There were no significant differences in terms of the mean age of the patients, male/female ratio, body mass index, and concurrent diseases between the drain group and the no-drain group. In addition, there were no significant differences in the tumor location, tumor diameter, depth of the tumor, nodal metastasis, and tumor stage between the two groups.

All patients in each group were successfully treated with RO surgery, and no patient required conversion to open surgery. Surgery-related factors, including lymph node dissection and operative time, were similar in the drain group and the no-drain group.

A comparison of the amount of intraoperative blood loss between patients with and without postoperative complications revealed that patients who experienced postoperative complications had a significantly larger amount of blood loss than those without postoperative complications.

A comparison of operative times between patients with and without surgery-related postoperative local complications revealed that patients who experienced surgery-related postoperative local complications had a significantly longer operative time than those without surgery-related postoperative local complications. Analysis of operative times in each group revealed that patients with surgery-related postoperative local complications had a significantly longer operative time than those without surgery-related postoperative local complications in the no-drain group.
\end{abstract}

Conclusions: Intraoperative factors such as the operative time and the amount of intraoperative blood loss affected the occurrence of postoperative complications following LDG. A prophylactic drain may thus be useful in patients at higher risk and in those with a longer operative time or massive intraoperative bleeding.

Keyword: Gastric cancer, Laparoscopic distal gastrectomy, Prophylactic drainage, Postoperative complication

\footnotetext{
* Correspondence: norinorihirahara@yahoo.co.jp

Department of Digestive and General Surgery, Shimane University Faculty of

Medicine, 89-1 Enya-cho, Izumo, Shimane 693-8501, Japan
} 


\section{Background}

The Guideline for Prevention of Surgical Site Infection (SSI), proposed by the Centers for Disease Control and Prevention (CDC) in 1999, recommends that 'If drainage is necessary, use a closed suction drain and remove the drain as soon as possible' [1]. Recent randomized controlled trials and meta-analyses have supported the limited use of prophylactic intra-abdominal drainage for many gastrointestinal surgeries [2-4]. In gastric surgery, drain placement is designed for the removal of fluid collections or for the early detection of postoperative bleeding, pancreatic fistulas, anastomotic leakage, and intra-abdominal infections. Incorrect use of an intra-abdominal drain can cause exudation of protein-rich ascitic fluid, which may lead to hypovolemia and hypoproteinemia, or facilitate retrograde bacterial contamination. With recent advances in interventional radiology, image-guided percutaneous drainage and aspiration procedures after the onset of complications now entail a low risk of intestinal injury [5]. Unnecessary drain placement must thus be avoided, but little is known about the value of prophylactic drainage following laparoscopic distal gastrectomy (LDG). In addition, surgeons often feel the need to place an intra-abdominal drain based on their intraoperative impression regarding factors such as the degree of difficulty of the surgical procedure and/or the level of surgical completeness and/or their own surgical experience. In this study, we investigated the significance of prophylactic intra-abdominal drain placement after LDG for gastric cancer.

\section{Methods \\ Patients}

Seventy-eight consecutive patients with gastric cancer who underwent LDG with a curative intent between January 2011 and April 2014 in our department were retrospectively analyzed. All operations were performed by the same operative team and were completed laparoscopically. The patients were divided into two groups according to the placement of a prophylactic intraabdominal drain following LDG. The 'drain group' comprised 45 patients who underwent LDG, from January 2011 to December 2012, with routine use of a prophylactic intra-abdominal drain. The 'no-drain group' comprised 33 patients who underwent LDG, from January 2013 to April 2014, without any intra-abdominal drain placement.

\section{Tumor staging}

The 'Japanese classification of gastric carcinoma: 3rd English edition' was used for tumor staging [6]. The appropriate extent of gastrectomy and lymphadenectomy (D1+ or D2) was determined according to the recommendation of the 'Japanese gastric cancer treatment guidelines 2010 (ver. 3)' [7].
Clinical classification of tumor depth and nodal involvement was evaluated using preoperative barium radiography, upper gastrointestinal tract endoscopy, abdominal ultrasonography, computed tomography $(\mathrm{CT})$, and endoscopic ultrasonography and was finally confirmed based on the pathologic findings.

\section{Indications for LDG}

Eligibility criteria included histologically proven adenocarcinoma of the gastric middle body or lower body, tumor status lower than T4b, no distant metastasis, and no lymph nodes larger than $1 \mathrm{~cm}$ in the hepatoduodenal ligament or in the paraaortic area. Exclusion criteria included carcinoma in the remnant stomach, linitis plastica, and synchronous or metachronous double cancers in the previous 10 years.

\section{Surgical technique}

The patient was placed in the supine position with legs apart, under a combination of epidural and general anesthesia. A 12-mm trocar was inserted by the open method in the umbilical region as a port for the camera. After the completion of pneumoperitonization with the carbon dioxide pressure at $8 \mathrm{mmHg}$, two additional 12$\mathrm{mm}$ trocars were inserted in the right lower and left upper abdomen and two 5-mm trocars were placed in the left lower and right upper abdomen.

Mobilization of the stomach and D1+ or D2 lymph node dissection were carried out in the conventional manner. The stomach and duodenum were divided with an endoscopic linear stapler (Endo GIA Ultra Universal stapler; Covidien, Mansfield, MA, USA). Typically, a two-thirds to four-fifths distal gastrectomy was performed. The dissected stomach was externalized through the umbilical incision, which was extended to approximately $4 \mathrm{~cm}$, and a side-to-side jejunojejunostomy was performed. Subsequently, an intracorporeal antecolic Roux-en Y reconstruction with an antiperistaltic gastrojejunostomy was completed.

In the drain group, a low-suction silicon drain (J-VAC: BLAKE Silicon Drain Kits; Ethicon, Inc., Somerville, NJ, USA) was placed in the foramen of Winslow via the right upper quadrant incision. The silicon drain has a solid-core structure with a three-dimensional core, which allows the lumen to retain its round shape, and four drainage channels inside the lumen. The suction bag has an internal spring structure, which provides constant and sustainable negative pressure.

\section{Postoperative management}

Patients in both groups were managed in the same manner using a standardized postoperative clinical protocol. Prophylactic antibiotics were administered every $6 \mathrm{~h}$ for $24 \mathrm{~h}$ from the beginning of surgery. As a rule, oral intake 
of water was initiated on the first day following the surgery, and liquid meals were resumed on postoperative day 5. All patients underwent upper gastrointestinal series (UGIs) with water-soluble contrast medium after surgery, and anastomotic leakage was defined based on the findings of UGIs or CT studies. Intra-abdominal abscess was defined as demonstrable fluid collection on $\mathrm{CT}$ in patients with high-grade fever or elevated serum C-reactive protein levels.

In principle, the silicon drain was removed after postoperative UGIs confirmed the absence of anastomotic leakage.

\section{Assessment of surgical and postoperative outcomes}

Surgical outcomes were evaluated in terms of extent of lymph node dissection, intraoperative blood loss, operation time, and requirement for blood transfusion.

Postoperative outcomes were evaluated in terms of postoperative days until the resumption of oral intake of fluids and food, time to first flatus and defecation, postoperative complications, and the length of the postoperative hospital stay. The postoperative complications comprised surgery-related local complications and systemic complications; the former included anastomotic or duodenal stump leakage, intra-abdominal abscess formation, wound infection, anastomotic edema, Roux-en $\mathrm{Y}$ stasis, and Petersen's hernia, and the latter included pulmonary infection and cerebral infarction.

All postoperative complications were monitored according to the Clavien-Dindo classification within 4 weeks of surgery [8], and any event of severity greater than grade II was counted as a postoperative complication.

\section{Risk assessment for the occurrence of postoperative complications}

To conduct the risk analysis, we assessed the impacts of operative time and intraoperative blood loss on the occurrence of postoperative complications, particularly surgeryrelated postoperative local complications.

\section{Statistical analysis}

Statistical analysis was performed using JMP statistical software (SAS Institute Inc., Cary, NC, USA). Values are expressed as the mean \pm standard deviation (SD). Comparisons between the two study groups were performed using Student's $t$-test, the chi-square test, the MannWhitney $U$-test, or Fisher's exact test as appropriate. For all tests, a $p$ value less than 0.05 was considered statistically significant.

Risk factors for the occurrence of postoperative complications were analyzed in relation to patients' preoperative conditions and intraoperative factors by logistic regression analysis.
Permission to perform this retrospective study was obtained from the ethical board of our institution.

\section{Results}

\section{Characteristics of the patients}

Forty-five and thirty-three patients were enrolled in the drain group and the no-drain group, respectively (Table 1). There were no significant differences in terms of the mean age of the patients, male/female ratio, body mass index, and concurrent diseases between the drain group and the no-drain group. In addition, there were no significant differences in the tumor location, tumor diameter, depth of the tumor, nodal metastasis, and tumor stage between the two groups.

\section{Operative data by group}

All patients in each group were successfully treated with R0 surgery, and no patient required conversion to open surgery. Surgical outcomes are summarized in Table 2. Surgery-related factors, including lymph node dissection and operative time, were similar in the drain group and the no-drain group. The no-drain group was associated with less intraoperative blood loss compared to the drain group, but the difference was not statistically significant. Eight patients in the drain group received blood transfusions, while two patients in the no-drain group required blood transfusions.

\section{Postoperative outcomes}

Postoperative outcomes are summarized in Table 3. There was no significant difference in the mean postoperative time interval to first flatus and defecation, whereas the time to first oral intake of fluids and food was shorter in the no-drain group (first intake of fluids, $p<0.0001$; first intake of food, $p=0.003)$. However, this result seemed to be due to a minor change in our postoperative clinical pathway in the middle of this study in January 2013.

Overall postoperative complications based on the Clavien-Dindo classification were recognized in 31.1\% and $30.3 \%$ of patients in the drain group and the nodrain group, respectively, and there was no significant difference in the rate of complications between the two groups $(p=0.892)$. There was no hospital mortality in this study, but one patient in the no-drain group who developed Petersen's hernia required reoperation on postoperative day 8 .

Regarding the postoperative hospital stay, no statistically significant difference was found between the drain group and the no-drain group. When taking the presence and absence of postoperative complications into consideration, the length of postoperative hospital stay did not differ between the two groups. 
Table 1 Characteristics of the patients

\begin{tabular}{|c|c|c|c|c|}
\hline & & $\begin{array}{l}\text { Drainage } \\
\text { group }\end{array}$ & $\begin{array}{l}\text { No-drainage } \\
\text { group }\end{array}$ & \\
\hline & & & $(n=33)$ & $p$ value \\
\hline Male:female & & $28: 17$ & $23: 10$ & $0.493 a$ \\
\hline Age (years) & & $70.5 \pm 13.4$ & $74.8 \pm 9.8$ & $0.125 b$ \\
\hline $\mathrm{BMI}\left(\mathrm{kg} / \mathrm{m}^{2}\right)$ & & $23.2 \pm 4.0$ & $23.2 \pm 4.0$ & $\begin{array}{l}23.2 \pm \\
4.0\end{array}$ \\
\hline \multicolumn{5}{|l|}{ Concurrent illness } \\
\hline None & & $7(15.6 \%)$ & $7(21.2 \%)$ & $0.520 a$ \\
\hline Arrhythmia & & $2(3.6 \%)$ & $5(15.2 \%)$ & \\
\hline $\begin{array}{l}\text { Ischemic heart } \\
\text { disease }\end{array}$ & & $7(12.7 \%)$ & $2(6.1 \%)$ & \\
\hline Hypertension & & $22(40.0 \%)$ & $12(36.4 \%)$ & \\
\hline Diabetes mellitus & & $6(10.1 \%)$ & $5(15.2 \%)$ & \\
\hline Cerebral infarction & & $4(7.3 \%)$ & $4(12.1 \%)$ & \\
\hline COPD & & $9(16.4 \%)$ & $6(18.2 \%)$ & \\
\hline Hyperlipidemia & & $9(16.4 \%)$ & $3(9.1 \%)$ & \\
\hline Other & & $7(12.7 \%)$ & $5(15.2 \%)$ & \\
\hline $\begin{array}{l}\text { Location of tumor } \\
\text { (M/L) }\end{array}$ & & $26 / 19$ & $14 / 19$ & $0.180 a$ \\
\hline $\begin{array}{l}\text { Diameter of tumor } \\
(\mathrm{mm})\end{array}$ & & $44.5 \pm 31.6$ & $39.0 \pm 19.3$ & $0.382 b$ \\
\hline \multirow{5}{*}{$\begin{array}{l}\text { Depth of tumor } \\
\text { invasion }\end{array}$} & $1 a$ & $11(24.4 \%)$ & $5(15.2 \%)$ & $0.177 a$ \\
\hline & $1 b$ & 13(28.9\%) & $12(36.4 \%)$ & \\
\hline & 2 & $6(13.3 \%)$ & $8(24.2 \%)$ & \\
\hline & 3 & $10(22.2 \%)$ & $2(6.1 \%)$ & \\
\hline & $4 a$ & $5(11.1 \%)$ & $6(18.2 \%)$ & \\
\hline \multirow{5}{*}{$\begin{array}{l}\text { Lymph node } \\
\text { metastasis }\end{array}$} & 0 & 33(73.3\%) & $23(69.7 \%)$ & $0.132 \mathrm{a}$ \\
\hline & 1 & $2(4.4 \%)$ & $6(18.2 \%)$ & \\
\hline & 2 & $5(11.1 \%)$ & $1(3.0 \%)$ & \\
\hline & $3 a$ & $5(11.1 \%)$ & $2(6.1 \%)$ & \\
\hline & $3 b$ & $0(0 \%)$ & $1(3.0 \%)$ & \\
\hline \multirow[t]{7}{*}{ Tumor stage } & $1 a$ & 24(53.3\%) & $14(42.4 \%)$ & $0.245 a$ \\
\hline & $1 b$ & $4(8.9 \%)$ & $9(27.3 \%)$ & \\
\hline & $2 a$ & $5(11.1 \%)$ & $1(3.0 \%)$ & \\
\hline & $2 b$ & $2(4.4 \%)$ & $4(12.1 \%)$ & \\
\hline & $3 a$ & $4(8.9 \%)$ & $2(6.1 \%)$ & \\
\hline & $3 b$ & $4(8.9 \%)$ & $2(6.1 \%)$ & \\
\hline & $3 c$ & $2(4.4 \%)$ & $1(3.0 \%)$ & \\
\hline
\end{tabular}

BMI body mass index, COPD chronic obstructive pulmonary disease, $\mathrm{M}$ middle, $L$ lower, a chi-square test, b Student's $t$-test.

\section{Risk assessment for the occurrence of postoperative} complications

Risk factors for the occurrence of postoperative complications were analyzed in relation to patients' preoperative conditions and intraoperative factors, but no useful
Table 2 Operative data per group

\begin{tabular}{llll}
\hline & $\begin{array}{l}\text { Drain group } \\
(\boldsymbol{n}=\mathbf{4 5})\end{array}$ & $\begin{array}{l}\text { No-drain group } \\
(\boldsymbol{n}=\mathbf{3 3})\end{array}$ \\
\hline Lymph node dissection & & \\
& D1+ & $25(55.6 \%)$ & $16(48.5 \%)$ \\
& D2 & $20(44.4 \%)$ & $17(51.5 \%)$ \\
Intraoperative blood loss (ml) & & $52.3 \pm 59.9$ & $40.8 \pm 85.7$ \\
Operation time (min) & & $408.5 \pm 84.5$ & $413.2 \pm 65.7$ \\
Blood transfusion & $8(17.8 \%)$ & $2(6.1 \%)$ \\
\hline
\end{tabular}

predictors of postoperative complications were identified (data not shown).

A comparison of operative time between patients with and without postoperative complications revealed that the patients with postoperative complications tended to have longer operative times than those without postoperative complications, but the difference was not significant $(p=0.121)$ (Table 4). Operative time was also compared between patients with and without postoperative complications in each group. No difference was found in the drain group, but patients who experienced postoperative complications in the no-drain group tended to have longer operative times than those without postoperative complications. However, the difference was not significant $(p=0.071)$.

A comparison of the amount of intraoperative blood loss between patients with and without postoperative complications revealed that patients who experienced postoperative complications had a significantly larger amount of blood loss than those without postoperative complications $(p=0.038)$. The same tendency was found when the volume of intraoperative blood loss was compared between patients with and without postoperative complications in each group, but the differences were not significant (Table 4).

\section{Risk assessment for the occurrence of surgery-related postoperative local complications}

A comparison of operative times between patients with and without surgery-related postoperative local complications revealed that patients who experienced surgeryrelated postoperative local complications had a significantly longer operative time than those without surgery-related postoperative local complications $(p=0.041)$ (Table 5). Analysis of operative times in each group revealed that patients with surgery-related postoperative local complications had a significantly longer operative time than those without surgery-related postoperative local complications in the no-drain group $(p=0.049)$.

A comparison of the amount of intraoperative blood loss between patients with and without surgery-related postoperative local complications revealed that patients 
Table 3 Postoperative outcomes

\begin{tabular}{|c|c|c|c|c|}
\hline & & $\begin{array}{l}\text { Drain } \\
\text { group } \\
(n=45)\end{array}$ & $\begin{array}{l}\text { No-drain } \\
\text { group } \\
(n=33)\end{array}$ & $p$ value \\
\hline First drinking, POD & & $3.6 \pm 3.1$ & $1.0 \pm 0.2$ & $<0.0001 a$ \\
\hline First eating, $P O D$ & & $6.6 \pm 3.2$ & $4.8 \pm 1.2$ & $0.002 \mathrm{a}$ \\
\hline First flatus, POD & & $2.2 \pm 1.6$ & $1.8 \pm 0.9$ & $0.136 b$ \\
\hline First defecation, POD & & $4.6 \pm 2.3$ & $3.8 \pm 1.5$ & $0.069 \mathrm{~b}$ \\
\hline Postoperative complication & & 14(31.1\%) & $10(30.3 \%)$ & $0.892 c$ \\
\hline \multicolumn{5}{|l|}{$\begin{array}{l}\text { Surgery-related local } \\
\text { complication }\end{array}$} \\
\hline Stump leakage & & $0(0 \%)$ & $2(6.1 \%)$ & \\
\hline Abscess & & $3(6.7 \%)$ & $1(3.0 \%)$ & \\
\hline Wound infection & & $4(8.9 \%)$ & $1(3.0 \%)$ & \\
\hline Anastomotic edema & & $3(6.7 \%)$ & $1(3.0 \%)$ & \\
\hline Stasis & & $4(8.9 \%)$ & $2(6.1 \%)$ & \\
\hline Petersen's hernia & & $0(0 \%)$ & $1(3.0 \%)$ & \\
\hline \multicolumn{5}{|l|}{ Systemic complication } \\
\hline Pulmonary infection & & $2(4.4 \%)$ & $1(3.0 \%)$ & \\
\hline Cerebral infarction & & $0(0 \%)$ & $1(3.0 \%)$ & \\
\hline $\begin{array}{l}\text { Postoperative hospital stay } \\
\text { (days) }\end{array}$ & & $16.4 \pm 8.1$ & $16.5 \pm 8.1$ & $0.982 b$ \\
\hline \multirow[t]{2}{*}{ Complication } & $(-)$ & $\begin{array}{l}13.2 \pm 3.4 \\
(n=31)\end{array}$ & $\begin{array}{l}12.3 \pm 2.5 \\
(n=23)\end{array}$ & $0.289 b$ \\
\hline & $(+)$ & $\begin{array}{l}24.5 \pm 10.5 \\
(n=14)\end{array}$ & $\begin{array}{l}26.1 \pm 8.6 \\
(n=10)\end{array}$ & $0.693 b$ \\
\hline \multirow[t]{2}{*}{ Local complication } & $(-)$ & $\begin{array}{l}13.5 \pm 3.4 \\
(n=34)\end{array}$ & $\begin{array}{l}13.3 \pm 4.2 \\
(n=25)\end{array}$ & $0.941 b$ \\
\hline & $(+)$ & $\begin{array}{l}26.0 \pm 10.7 \\
(n=11)\end{array}$ & $\begin{array}{l}26.5 \pm 9.6 \\
(n=8)\end{array}$ & $0.917 b$ \\
\hline
\end{tabular}

POD postoperative day, a Mann-Whitney U-test, b Student's $t$-test, c Chi-square test. who experienced surgery-related postoperative local complications had a larger amount of blood loss than those without surgery-related postoperative local complications, but the difference was not significant $(p=0.490)$.

\section{Discussion}

It is a well-known fact that the CDC guideline recommends a closed suction drain for the prevention of SSI [1], and this recommendation is based on the literature by Moro et al. which reported that leaving an open drain in place for 3 days or longer is a risk factor for SSI $[9,10]$. As the microbial biomass in drains is reported to increase with time, even in a closed drain, it is important to remove the drain as soon as possible [9]. However, applying the CDC guideline to gastrointestinal surgery may entail some problems because the abovementioned studies were restricted to cardiovascular surgery with clean or Class 1 wounds, which differs from gastrointestinal surgery in terms of the situation regarding drain placement. In other words, it is questionable whether it would be appropriate to apply the same standard for these two different surgeries, that is, clean and cleancontaminated operations.

Laparoscopy-assisted distal gastrectomy, first introduced in 1991, has now been standardized and stabilized with safety [11]. Conventionally, an intra-abdominal drain has been routinely placed following gastrectomy for the purpose of early detection of postoperative bleeding, anastomotic leakage, and intra-abdominal infections. Although the routine use of a drain or catheter is considered to be unnecessary from the perspective of recent Enhanced Recovery After Surgery (ERAS) guidelines, no high-quality evidence exists regarding whether an intra-abdominal drain would prevent and alleviate postoperative complications after laparoscopy-assisted distal gastrectomy. Ishikawa et al. reported that routine prophylactic abdominal drainage following laparoscopy-assisted distal gastrectomy for early gastric cancer may not be necessary [12]. Furthermore, Albanopoulos et al. reported that placement of

Table 4 Risk assessment for the occurrence of postoperative complication

\begin{tabular}{|c|c|c|c|}
\hline & \multicolumn{2}{|c|}{ Postoperative complication } & \multirow[b]{2}{*}{$p$ value } \\
\hline & $(-)$ & $(+)$ & \\
\hline \multicolumn{4}{|l|}{ Operation time (min) } \\
\hline All cases & $401.8 \pm 79.2(n=55)$ & $431.3 \pm 67.3(n=23)$ & $0.121 a$ \\
\hline Drain group $(n=45)$ & $403.3 \pm 88.1(n=31)$ & $421.3 \pm 76.5(n=14)$ & $0.524 a$ \\
\hline No-drain group $(n=33)$ & $399.6 \pm 66.7(n=23)$ & $444.4 \pm 54.2(n=10)$ & $0.071 a$ \\
\hline \multicolumn{4}{|l|}{ Intraoperative blood loss (ml) } \\
\hline All cases & $38.2 \pm 51.0(n=55)$ & $69.6 \pm 104.3(n=23)$ & $0.038 a$ \\
\hline Drain group $(n=45)$ & $47.3 \pm 55.8(n=31)$ & $64.6 \pm 69.7(n=14)$ & $0.386 a$ \\
\hline No-drain group $(n=33)$ & $25.4 \pm 41.2(n=23)$ & $76.0 \pm 141.4(n=10)$ & $0.121 a$ \\
\hline
\end{tabular}

a Student's $t$-test. 
Table 5 Risk assessment for the occurrence of surgery-related postoperative local complication

\begin{tabular}{|c|c|c|c|}
\hline & \multicolumn{2}{|c|}{ Surgery-related local complication } & \multirow[b]{2}{*}{$p$ value } \\
\hline & $\overline{(-)}$ & $(+)$ & \\
\hline \multicolumn{4}{|l|}{ Operation time(min) } \\
\hline All cases & $402.0 \pm 77.6(n=59)$ & $436.9 \pm 69.0(n=19)$ & $0.041 a$ \\
\hline Drain group $(n=45)$ & $401.6 \pm 85.7(n=33)$ & $429.9 \pm 80.6(n=12)$ & $0.340 \mathrm{a}$ \\
\hline No-drain group $(n=33)$ & $402.5 \pm 66.8(n=25)$ & $446.6 \pm 52.9(n=8)$ & $0.049 a$ \\
\hline \multicolumn{4}{|l|}{ Intraoperative blood loss(ml) } \\
\hline All cases & $44.2 \pm 61.2(n=59)$ & $57.4 \pm 98.8(n=19)$ & $0.490 \mathrm{a}$ \\
\hline Drain group $(n=45)$ & $50.7 \pm 55.8(n=33)$ & $57.3 \pm 73.7(n=12)$ & $0.756 a$ \\
\hline No-drain group $(n=33)$ & $35.4 \pm 68.0(n=25)$ & $57.5 \pm 131.7(n=8)$ & $0.534 a$ \\
\hline
\end{tabular}

intra-abdominal drains after laparoscopic sleeve gastrectomy does not facilitate detection of leaks and abscesses [13]. Such complications can be diagnosed by clinical and radiological findings. Thus, our department performed LDG without any intra-abdominal drain placement from January 2013. Because little information is available on routine prophylactic drainage after LDG [14,15], this study investigated the influence of the presence or absence of prophylactic intra-abdominal drain placement on the postoperative outcomes in patients who underwent LDG for gastric cancer.

Although postoperative complications were recognized in about $30 \%$ of patients in both the drain group and the no-drain group in the current study, no anastomotic leakage was observed for either gastrojejunostomy or jejunojejunostomy after LDG. Anastomotic leakage following gastrectomy, which requires early detection and subsequent appropriate measures, is a rare type of postoperative complication with a rate of occurrence of around 1\% [16]. Moreover, we could not confirm any advantage associated with prophylactic drain placement in relation to anastomotic insufficiency after LDG. Meanwhile, intra-abdominal abscess and SSI occurred more frequently in the drain group, suggesting that retrograde infections through the drain or drainage failure in cases with pancreatic fistulas may be involved in such infectious complications. Among three patients who developed intra-abdominal abscesses in the drain group, only one patient required interventional radiology for abscess drainage, while the other two patients were successfully managed with antibiotics and fasting. Only one patient who developed an intra-abdominal abscess in the no-drain group was intensively treated with broad-spectrum antibiotics and fasting. Administration of broad-spectrum antibiotics could be a good conservative management strategy. Based on these facts, prophylactic drainage following LDG may not always be practical for the reduction of postoperative surgeryrelated postoperative local complications.
Placement of a prophylactic drain following LDG had no impact on the length of the postoperative hospital stay in this study. Among the patients who experienced postoperative complications, however, we found that patients in the drain group tended to have a shorter postoperative hospital stay than those in the no-drain group. This finding suggests the possibility that drainage would be effective in patients who experienced surgery-related postoperative local complications.

Predicting the risk factors for postoperative complications after LDG by utilizing patients' preoperative conditions was not successful in this study. On the other hand, intraoperative factors such as the operative time and the amount of intraoperative blood loss affected the occurrence of postoperative complications following LDG. The postoperative risk assessment should thus include intraoperative factors as well as patients' preoperative conditions. A prophylactic drain may be useful in patients at higher risk, for example, patients with a longer operative time or massive intraoperative bleeding. At present, placement of a prophylactic drain should be decided with consideration of hospital volume, surgeon volume, skill of the individual surgeon, risks of postoperative complications, and a backup system when complications occur. Prospective randomized studies with large sample sizes should be conducted to evaluate the significance of prophylactic intra-abdominal drains following LDG.

\section{Conclusions}

A prophylactic drain may be useful in patients at higher risk and in those with a longer operative time or massive intraoperative bleeding.

\section{Competing interests}

The authors declare that they have no competing interests.

\section{Authors' contributions}

$\mathrm{NH}$ was the lead author and surgeon for all of the patients. TM, HH, KT, and YF contributed to patient recruitment and provided information on the patients. YT reviewed the paper and the surgical technique. All authors read and approved the final manuscript. 


\section{Acknowledgements}

The authors thank Takeshi Matsubara, Hikota Hayashi, Kiyoe Takai, and Yusuke Fujii for contributing to patient recruitment and providing information on the patients. We are also grateful to Takeshi Matsubara and Yusuke Fujii for acting as co-surgeons for the cases. The authors received the generous support and encouragement of Yoshitsugu Tajima in correcting the English used in this manuscript.

Received: 14 December 2014 Accepted: 24 April 2015

Published online: 12 May 2015

\section{References}

1. Mangram AJ, Horan TC, Pearson ML, Siver LC, Jarvis WR. Guideline for prevention of surgical site infection, 1999. Hospital Infection Control Practices Advisory Committee. Infect Control Hosp Epidemiol. 1999;1999(20):247-78.

2. Petrowsky H, Demartines N, Rousson V, Clavien PA. Evidence-based value of prophylactic drainage in gastrointestinal surgery: a systemic review and meta-analyses. Ann Surg. 2004;240:1074-85.

3. Liu CL, Fan ST, Lo CM, Wong Y, Ng IO, Lam CM, et al. Abdominal drainage after hepatic resection is contraindicated in patients with chronic liver diseases. Ann Surg. 2004;239:194-201.

4. Fong Y, Brennan MF, Brown K, Heffernan N, Blumgart LH. Drainage is unnecessary after liver resection. Am J Surg. 1996;171:158-62.

5. Burt BM, Brown K, Jarnagin W, DeMatteo R, Blumgart LH, Fong Y. An audit of results of a no-drainage practice policy after hepatectomy. Am J Surg. 2002;184:441-5.

6. Japanese Gastric Cancer Association. Japanese classification of gastric carcinoma: 3rd English edition. Gastric Cancer. 2011;14:101-12.

7. Japanese Gastric Cancer Association. Japanese gastric cancer treatment guidelines 2010 (ver.3). Gastric Cancer. 2011;14:113-23.

8. Clavien PA, Barkun J, de Oliveira ML, Vauthey JN, Dindo D, Schulick RD, et al. The Clavien-Dindo classification of surgical complications: five-year experience. Ann Surg. 2009;250:187-96.

9. Moro ML, Carrieri MP, Tozzi AE, Lana S, Greco D. Risk factors for surgical wound infection in clean surgery: a multicenter study. Ann Ital Chir. 1996;67:13-9.

10. Drinkwater CJ, Neil MJ. Optimal timing of wound drain removal following total joint arthroplasty. J Arthroplasty. 1995;10:185-9.

11. Kitano S, Iso Y, Moriyama M, Sugimachi K. Laparoscopy-assisted Billroth-I gastrectomy. Surg Laparosc Endosc. 1994;4:146-8.

12. Ishikawa K, Matsumata T, Kishihara F, Fukuyama Y, Masuda H. Laparoscopy-assisted distal gastrectomy for early gastric cancer with versus without prophylactic drainage. Surg Today. 2011;41:1049-53.

13. Albanopoulos K, Alevizos L, Linardoutsos D, Menenakos E, Stamou K, Vlachos D, et al. Routine abdominal drains after laparoscopic sleeve gastrectomy: a retrospective review of 353 patients. Obes Surg.

14. Kim J, Lee J, Hyung WJ, Cheong JH, Chen J, Choi SH, et al. Gastric cancer surgery without drains: a prospective randomized trial. J Gastrointest Surg. 2004;8:727-32.

15. Kumar M, Yang SB, Jaiswal VK, Shah JN, Shreshtha M, Gongal R. Is prophylactic placement of drains necessary after subtotal gastrectomy? World J Gastroenterol. 2007;13:3738-41.

16. Sierzega M, Kolodziejczyk P, Kulig J. Polish Gastric Cancer Study Group. Impact of anastomotic leakage on long-term survival after gastrectomy for carcinoma of the stomach. Br J Surg. 2010;97:1035-42.

\section{Submit your next manuscript to BioMed Central and take full advantage of:}

- Convenient online submission

- Thorough peer review

- No space constraints or color figure charges

- Immediate publication on acceptance

- Inclusion in PubMed, CAS, Scopus and Google Scholar

- Research which is freely available for redistribution 